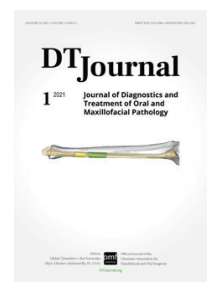

\title{
IMAGES
}

Camilo Mosquera, DDS, Editor

\section{| Periorbital Abscessing Furuncle}

\author{
Olha S. Cherniak \& levgen I. Fesenkob,c
}

\begin{abstract}
After plucking eyebrows a 27-year-old female patient noted left eyelid swelling, redness, increasing of pain and body temperature with no visual deficits. The examination showed the presence of crust (Panel A: arrow) just below the medial part of the left eyebrow. Ultrasonography (model HD11 XE, Philips) was performed using linear transducer (frequency range: $12-3 \mathrm{MHz}$ ) in the supine position of the patient. Firstly, a comparative gray scale ocular ultrasound (US) of the right (Panel B) and left eye (Panel C) showed only a soft tissue hypoechoic swelling anteriorly to the left eye. Increased distance (due to edema) between skin surface and cornea is labeled by vertical line. But placing the transducer in the projection of the crust and parallel to the left eyebrow (Panel D) the gray scale US (Panel E) showed fluctuated nearly anechoic heterogenic area with ill-defined margins (indicated by ' + ' and ' $x$ ' calipers) measured $1.21 \times 1.06 \mathrm{~cm}$. Such data suggested presence of limited purulent content. Furuncle (also known as boil) is a single hair follicle-associated bacterial infection (in 96 to 98 percent caused by Staphylococci [in 88-90 percent by Staphylococcus aureus and in 6-10 percent - by Staphylococcus epidermidis] $)^{2}$ of the perifollicular
\end{abstract}

\footnotetext{
Kyiv, Ukraine

a Physician of Ultrasound Diagnostics; Head, Department of Ultrasound, Regional Diagnostic Center, Kyiv Regional Clinical Hospital. cherniak.os@gmail.com

${ }^{b}$ Physician-Stomatologist-Surgeon, Physician of Ultrasound Diagnostics, Center of Maxillofacial Surgery and Dentistry, Kyiv Regional Clinical Hospital (place of work at moment of material collection). i.i.fesenko@dtjournal.oro

c $\mathrm{PhD}$, Associate Professor, Department of Oral and Maxillofacial Surgery, Private Higher Educational Establishment "Kyiv Medical University."
}

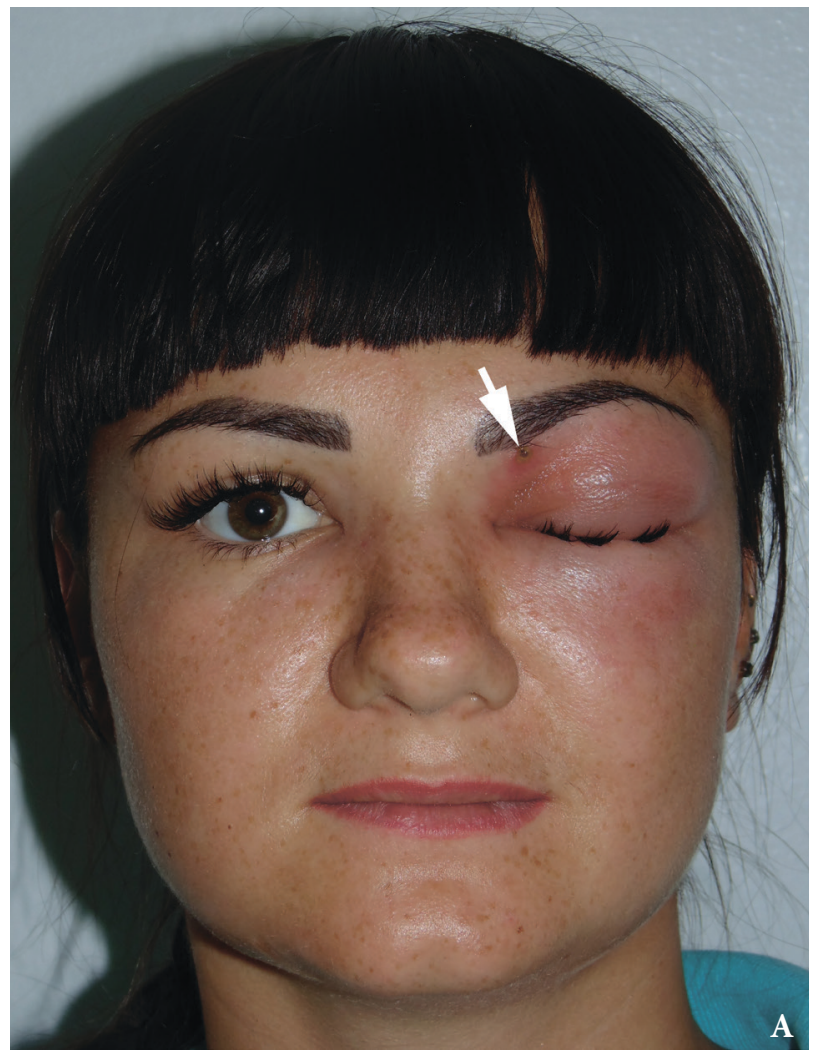

Please cite this article as: Cherniak OS, Fesenko II. Periorbital abscessing furuncle. J Diagn Treat Oral Maxillofac Pathol 2021;5(1):13-4.

\section{Paper received 5 January 2021 \\ Accepted 14 January 2021}

Available online 29 January 2021

https://dx.doi.org/10.23999/j.dtomp.2021.1.4

(c) 2021 OMF Publishing, LLC. This is an open access article under the CC BY license (http://creativecommons.org/licenses/by-nc/4.0/). 


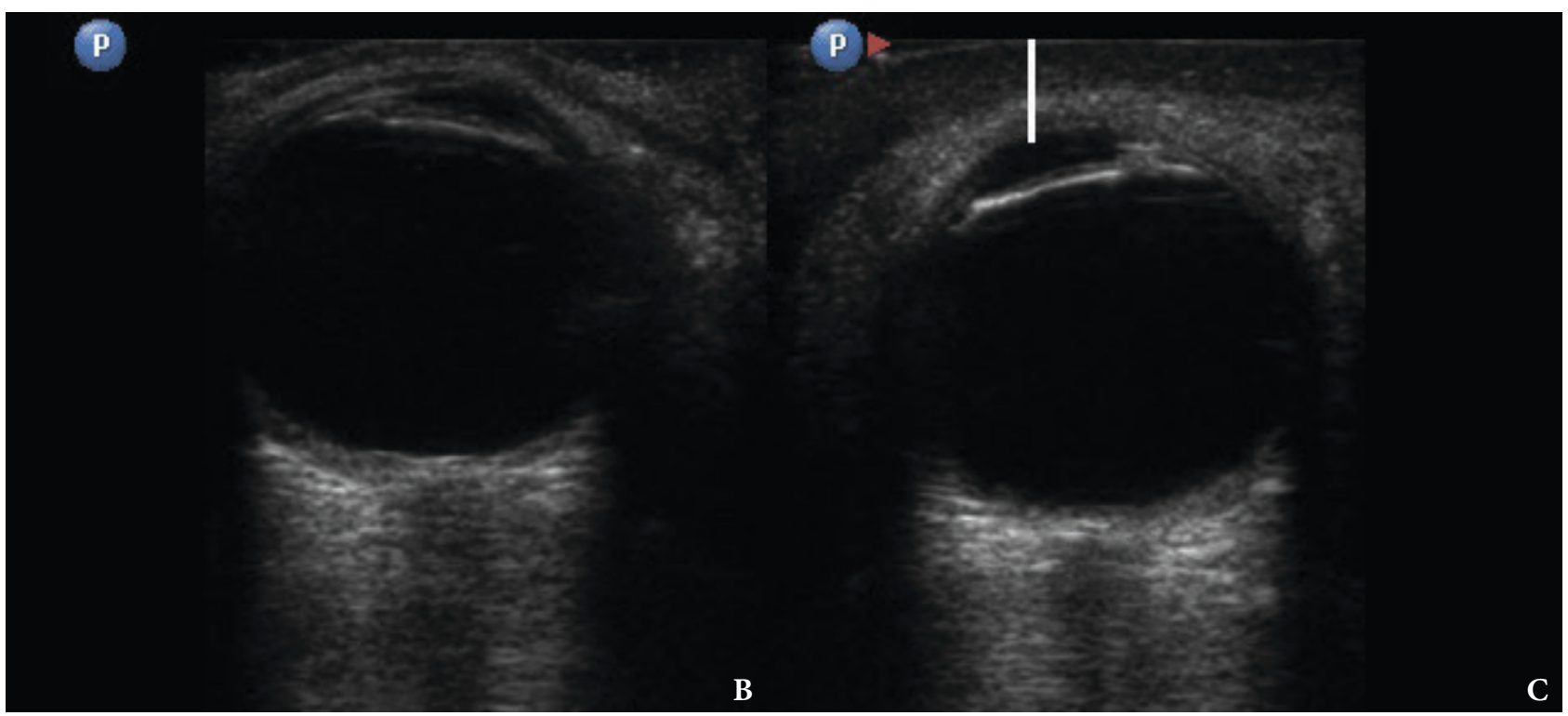

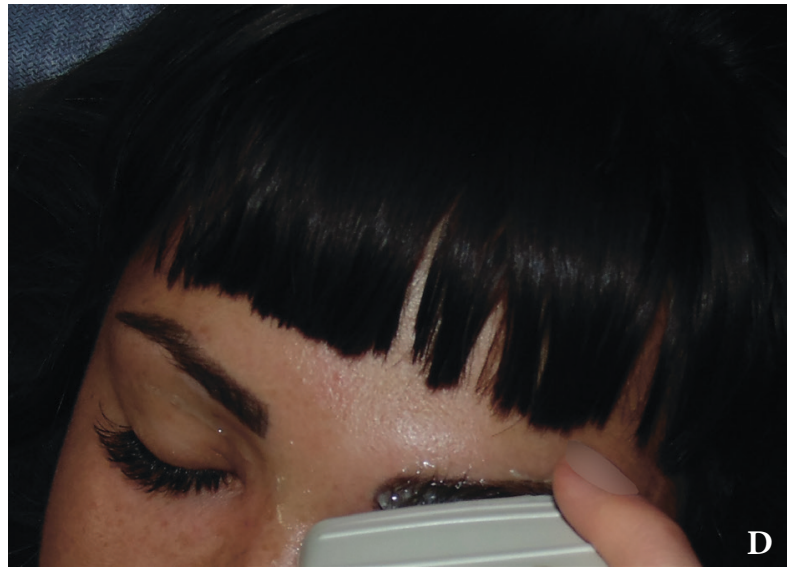

tissue. ${ }^{1,3}$ Also, furuncle is named in the literature as acute purulent-necrotic inflammation of the single hair follicle and surrounding tissue. ${ }^{2}$ Abscessing (ie, fluctuating) furuncles require its drainage what was done in our case under the local anesthesia with a several days rubber drainage placement. ${ }^{1,}$ Intramuscular ceftriaxone was prescribed ( $2.0 \mathrm{~g}$ daily) and complete recovery was noted at 7-day followup. Summarizing, orbital US continues to prove its efficacy in the wide variety of orbital inflammatory cases $^{4,5}$ becoming a viable tool during the different stages of treatment. = DTJournal

\section{REFERENCES}

1. Lin HS, Lin PT, Tsai YS, Wang SH, Chi CC. Interventions for bacterial folliculitis and boils

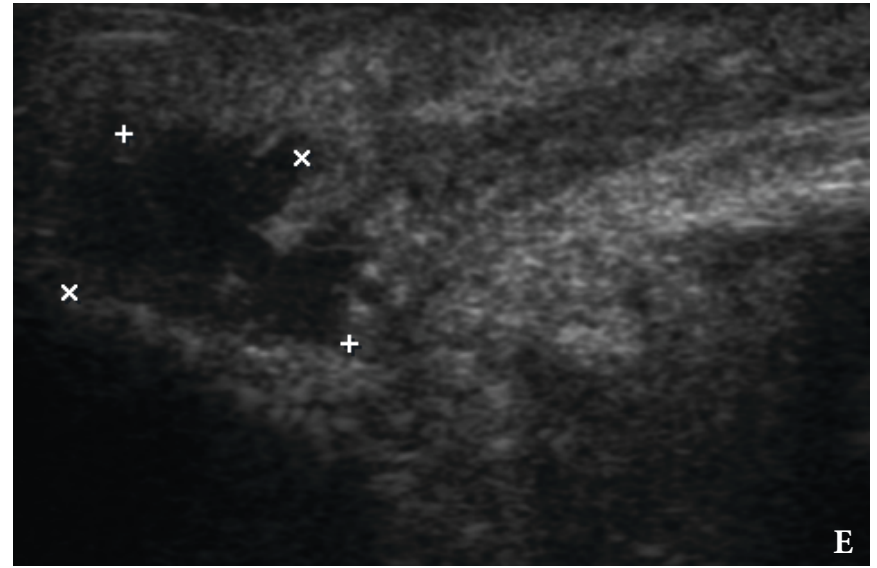

(furuncles and carbuncles). Cochrane Database Syst Rev 2018;2018(8):CD013099. https://doi. org/10.1002/14651858.CD013099

2. Tymofieiev OO. Maxillofacial surgery and surgical dentistry [Russian]. Kyiv, Ukraine: Medicine; 2020.

3. Lopez FA, Lartchenko S. Skin and soft tissue infections. Infect Dis Clin N Am 2006;20(4):759-72. https://doi.org/10.1016/j.idc.2006.09.006

4. Mair MH, Geley T, Judmaier W, Gassner I. Using orbital sonography to diagnose and monitor treatment of acute swelling of the eyelids in pediatric patients. AJR Am J Roentgenol 2002;179(6):1529-34. https://doi.org/10.2214/ajr.179.6.1791529

5. McIlrath ST, Blaivas $M$, Lyon $M$. Diagnosis of periorbital gas on ocular ultrasound after facial trauma. Am J Emerg Med 2005;23(4):517-20. https:// doi.org/10.1016/j.ajem.2004.10.001 